$x-641-66-432$

NAPA TIME 55753

3RARE-EARTH AND BARIUM ABUNDANCES IN THE BUNUNU HOWARDITE 6

BY

6 JOHN A. PHILPOTTS

C. C. SCHNITZLER

H. H. THOMAS 9

9 OCTOBER 196610

INASA

GODDARD SPACE FLIGHT CENTER GREENBELT, MARYLAND 3

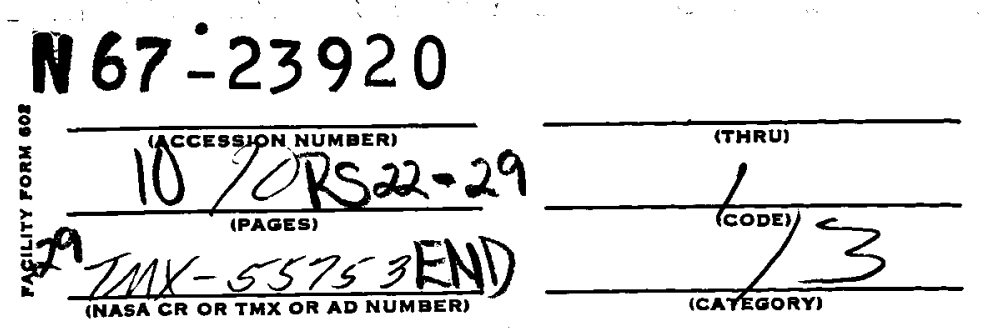




\title{
RARE-EARTH AND BARIUM ABUNDANCES IN THE BUNUNU HOWARDITE
}

\author{
John A. Philpotts \\ C. C. Schnetzler \\ H. H. Thomas \\ Geochemistry Laboratory \\ Laboratory for Theoretical Studies \\ Goddard Space Flight Center \\ Greenbelt, Maryl and
}

Abundances of the rare-earth elements and barium in the Bununu howardite (U. S. National Museum \#1571) have been determined by massspectrometric stable-isotope dilution (1). Briefly, the analytical technique consists of dissolving the sample, adding isotopic "spikes" of the rare-earths and barium, and concentrating these elements by passing the solution through an ion-exchange column. No attempt was made to separate the rare-earths from each other or from other elements with similar partition coefficients. Isotopic analysis was done with a triple-filament, solid-source mass-spectrometer.

The results of the rare-earth and barium analyses are given in Table 1. The precisions $(\bar{\sigma})$ shown are only internal in that they are the standard deviation of the mean of the number of determinations ( $n$ ), each determination being calculated from two scans of the appropriate mass region. The data have been normalized to hypothetical chondritic abundances based on a comparison of the analyses of rare-earths in eucrites by Schmitt et al. $(2,3)$ with our unpublished analyses. For comparison, the data also have been normalized to the average rare-earth abundances in chondrites determined by neutron activation by Schmitt et al. (3) and the average barium abundance determined by Reed et al. (4). The two sets of normalized data agree within $15 \%$. The normalized abundances of the rare-earths and barium in Bununu are shown in Fig. 1; the error bars denote plus and minus two standard deviations of the mean. 


\section{Table 1}

Rare-Earth and Barium Abundances in the Bununu Howardite

ppm $\quad \bar{\sigma}$

$\mathrm{Ba}$

$\mathrm{Ce}$

Nd

Sm

Eu

Gd

Dy

Er

$\mathrm{Yb}$
18.5

4.02

3.31

1.064

0.357

1.289

1.558

0.92

0.984
0.12

0.064

0.024

0.0071

0.0010

0.0070

0.0065

0.014

0.0048 n

16

4

16

12

5

12

12

8

12
Normalized Normalized to

Chondrite Avg. (3)

5.43

4.78

5.08

5.91

5.12

5.32

5.03

4.96

5.04

4.44

5.14

5.19

5.08

4.42

5.23

5.79 
The Bununu meteorite fell in central Nigeria in 1942. A petrographic and chemical description has been given by Mason (5). The dominance of hypersthene over pigeonite and the chemical composition show that Bununu is a howardite rather than a eucrite.

Bununu is the first howardite to be analyzed for the rare-earths. Because of the considerable confusion in the criteria of distinction between eucrites and howardites (5), Schmitt et al. (2) incorrectly termed Neuvo Laredo a howardite in reporting its rare-earth contents. The normalized plot in Fig. 1 of the rare-earths and barium in Bununu shows that although the absolute abundances are some five times higher than those in the average chondrite, the relative abundances of these elements are the same as those in chondrites. The Bununu howardite is therefore one of a group of meteorites including chondrites, mesosiderites and eucrites $(2,3)$ in which the rare earths have the same relative abundances. This group might be termed an "unfractionated sequence." The ranges of published normalized rare-earth abundances for the members of this "unfractionated sequence" are shown in Fig. 1; the mesosiderite data were determined only on the silicate phases.

The chemical and petrographic variations found in the calcium-rich achondrites (eucrites and howardites) have been interpreted in terms of igneous differentiation processes $(5,6,7,8)$, perhaps with fractional volatilization playing a role (9). The trace element data on these meteorites impose strict limitations on the type of differentiation that may have occurred and serve to distinguish the meteoritic "trend" from some types of terrestrial igneous differentiation in which relative fractionation of the rare-earths has occurred. 
If the calcium-rich achondrites and perhaps the mesosiderites belong to a co-genetic igneous sequence, then their unfractionated rare-earth patterns permit only two possible types of residual solid: (a) a solid, composed of one or more phases, which contains significant amounts of rare-earths relative to the melt but which is itself unfractionated, or (b) a solid which, compared to the melt, is so depleted in rare-earths that their relative abundances in the solid would have a negligible affect on those in the melt. The first possibility would entail the subtraction of a member of the "unfractionated" meteorite sequence from another member with higher rare-earth abundances (assuming that the rare-earth partition coefficients are less than unity) to produce another member with still higher rare-earth abundances. Our unpublished analyses of rare-earths in the two dominant phases of the eucrites, pigeonite and plagioclase, however, show both to have fractionated patterns. Such a differentiation scheme would therefore involve a solid with a surprising balance between the proportions of these two phases and their rare-earth contents. In addition, the meteorite sequence is not only unfractionated for the rare-earths and barium but published data indicate that it is also probably essentially unfractionated for a number of other elements including uranium (4), thorium (10), yttrium (2, 3), strontium (11, 12 , 13), and titanium $(8,14,15)$; that is, the relative abundances of these elements are essentially the same throughout the sequence.

It therefore seems more probable that this meteorite sequence originated through the subtraction of a solid with very low abundances of the rare-earths (and the other unfractionated trace elements). Rareearth data $(2,3)$ indicate that this solid might be either olivine or 
hypersthene. The lack of any great variation in the silica contents of the calcium-rich achondrites $(5,6,7,8)$ favors hypersthene. Thus one can imagine the subtraction of hypersthene from a howardite melt during igneous differentiation resulting in an eutectoid eucrite melt. Conversely howardites might represent a mixture of eucrite me1t and solid hypersthene. In view of the brecciation of most calcium-rich achondrites, a mechanical mixture of eucrite and hypersthene achondrites (diogenites) is also possible. On the basis of petrographic and major-element chemical criteria alone, the probable genetic relation between hypersthene achondrites and calcium-rich achondrites has been recognized $(5,6,7,8)$. The rare-earth data support this relationship and indicate further that the proportion of pigeonite to plagioclase is essentially the same throughout the sequence.

Rare-earth abundances in oceanic tholeiites (16) and our unpublished data on basic and ultrabasic rocks suggest that a similar "unfractionated sequence" exists for terrestrial rocks.

We thank Roy Clarke and Brian Mason of the U. S. National Museum for donating the sample of Bununu used in this investigation. 


\section{REFERENCES}

(1) C. C. Schnetzler, H. H. Thomas and John A. Philpotts, Rare-earth analysis by a mass-spectrometric isotope dilution technique, in preparation (1966).

(2) R. A. Schmitt, R. H. Smith, J. E. Lasch, A. W. Mosen, D. A. Olehy and J. Vasilevskis, Abundances of the fourteen rare-earth elements, scandium, and yttrium in meteoritic and terrestrial matter, Geochim. Cosmochim. Acta 27 (1963) 577.

(3) R. A. Schmitt, R. H. Smith and D. A. Olehy, Rare-earth, yttrium and scandium abundances in meteoritic and terrestrial matter - II, Geochim. Cosmochim. Acta 28 (1964) 67.

(4) G. W. Reed, K. Kigoshi and A. Turkevich, Determinations of concentrations of heavy elements in meteorites by activation analysis, Geochim. Cosmochim. Acta 20 (1960) 122 .

(5) Brian Mason, The Bununu meteorite, and a discussion of the pyroxeneplagioclase achondrites, submitted to Geochim. Cosmochim. Acta (1966).

(6) C. B. Moore, The petrochemistry of the achondrites, Researches on meteorites (Wiley, New York, 1962) 164.

(7) Brian Mason, Meteorites (Wiley, New York, 1962) 116.

(8) M. B. Duke, Petrology of the basaltic achondrites, Ph.D. dissertation, California Institute of Technology (1963).

(9) Paul W. Gast, Terrestrial ratio of potassium to rubidium and the composition of the earth's mantle, Science 147 (1965) 858.

(10) G. L. Bate, J. R. Huizenga and H. A. Potratz, Thorium in stone meteorites by neutron activation analysis, Geochim. Cosmochim. Acta 16 (1959) 88 . 
(11) L. F. Herzog and W. H. Pinson, Rb/Sr age, elemental and isotopic abundance studies of stony meteorites, Am. J. Sci. 254 (1956) 555.

(12) P. W. Gast, The isotopic composition of strontium and the age of stone meteorites - 1, Geochim. Cosmochim. Acta 26 (1962) 927.

(13) W. H. Pinson, Jr., C. C. Schnetzler, E. Beiser, H. W. Fairbairn and P. M. Hurley, Rb-Sr age of stony meteorites, Geochim. Cosmochim. Acta 29 (1965) 455.

(14) H. B. Wiik, The chemical composition of some stony meteorites, Geochim. Cosmochim. Acta $\underline{9}$ (1956) 279.

(15) C. B. Moore and H. Brown, The distribution of manganese and titanium in stony meteorites, Geochim. Cosmochim. Acta 26 (1962) 495.

(16) Fred A. Frey and Larry Haskin, Rare earths in oceanic basalts, J. Geophys. Res. 69 (1964) 775 . 


\section{FIGURE CAPTIONS}

Figure 1 Chondrite-normalized rare-earth and barium abundances in the Bununu howardite. The ranges for published analyses of encrites, mesosiderites and chondrites are indicated by the cross-hatched areas. 


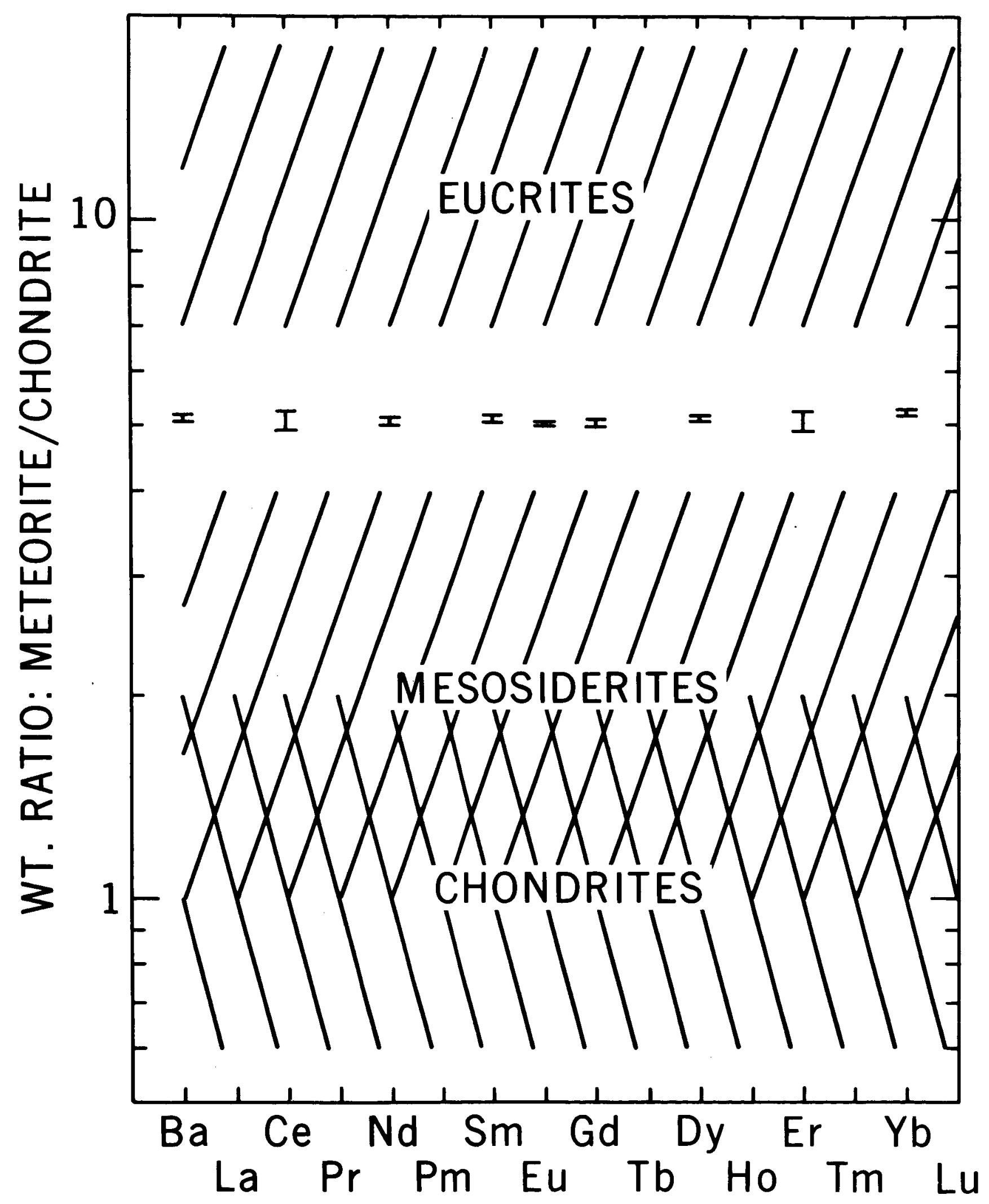

